\title{
Correction to: Generalized Ricci soliton and paracontact geometry
}

\author{
Devaraja Mallesha Naik ${ }^{1} \cdot$ V. Venkatesha ${ }^{2}$ (I) H. Aruna Kumara ${ }^{2}$
}

Published online: 23 August 2021

(C) Instituto de Matemática e Estatística da Universidade de São Paulo 2021

\section{Correction to: São Paulo Journal of Mathematical Science https://doi.org/10.1007/s40863-021-00260-1}

This article was updated to correct Reference 17.

Publisher's Note Springer Nature remains neutral with regard to jurisdictional claims in published maps and institutional affiliations.

The original article can be found online at https://doi.org/10.1007/s40863-021-00260-1.

\section{Venkatesha}

vensmath@gmail.com

Devaraja Mallesha Naik

devaraja.mallesha@christuniversity.in; devarajamaths@gmail.com

H. Aruna Kumara

arunmathsku@gmail.com

1 Department of Mathematics, CHRIST (Deemed to be University), Bengaluru, Karnataka, India

2 Department of Mathematics, Kuvempu University, Shankaraghatta, Karnataka 577-451, India 